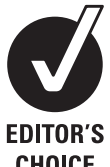

CHOICE

\title{
Nonsense mutation of the stereociliar membrane protein gene PTPRO in human hearing loss DFNB84
}

\author{
Hashem Shahin, ${ }^{1}$ Michael Rahil, ${ }^{2}$ Amal Abu Rayan, ${ }^{1}$ Karen B Avraham, ${ }^{3}$ \\ Mary-Claire King, ${ }^{4}$ Moien Kanaan, ${ }^{1}$ Tom Walsh ${ }^{4}$
}

\begin{abstract}
- Additional figures and tables are published online only. To view these files please visit the journal online (http://jmg.bmj. com).

${ }^{1}$ Department of Life Sciences, Bethlehem University, Bethlehem, Palestinian National Authority

${ }^{2}$ Dar Al-Kalima Health and Wellness Center, Bethlehem, Palestinian National Authority ${ }^{3}$ Department of Human Molecular Genetics and Biochemistry, Sackler School of Medicine, Tel Aviv University, Tel Aviv, Israel

${ }^{4}$ Department of Medicine, Division of Medical Genetics, University of Washington, Seattle, WA, USA
\end{abstract}

\section{Correspondence to}

Dr Tom Walsh, University of Washington, Division of Medical Genetics, Box 357720, Seattle, WA 98195, USA:

twalsh@uw.edu

Received 3 December 2009 Revised 17 December 2009 Accepted 22 December 2009 Published Online First 14 May 2010

\section{ABSTRACT}

Background Moderate to severe prelingual hearing impairment (DFNB84) was observed in an extended consanguineous Palestinian kindred. All affected relatives shared a 12.5 MB homozygous haplotype on chromosome 12q21 with lod score 4.30. This homozygous region harbours the protein tyrosine phosphatase receptor 0 gene $P T P R Q$, which is known to be essential to hearing in mouse.

Methods Candidate genes in the $12.5 \mathrm{MB}$ homozygous region were characterized genomically and sequenced in deaf and hearing relatives in the family.

Results Sequence of PTPRO in affected individuals in the extended kindred revealed c.1285C $\rightarrow T$, leading to p.Gln429Stop. This nonsense mutation co-segregated with hearing loss in the family and was homozygous in all affected relatives. The mutation did not appear among 288 Palestinian controls (576 chromosomes), all adults with normal hearing. No homozygous mutations in PTPRO appeared in any of 218 other probands with hearing loss.

Conclusion Identification of the DFNB84 gene represents the first identification of PTPRO mutation in human hearing loss.

Hair cells of the inner ear are specialised mechanoreceptor cells that detect sound and head movement. The mechanical to electrical transduction is accomplished specifically by the hair bundle, comprised of approximately 100 actin filled stereocilia. Proteins of the stereociliar membrane include ion channels, chemoreceptors and cell adhesion molecules. One stereociliar membrane protein is PTPRQ (protein tyrosine phosphatase receptor type $Q$ ), which includes an extracellular domain containing 18 fibronectin III (FNIII) repeats, a membrane spanning domain, and a cytoplasmic domain with phosphatidylinositol phosphatase activity. ${ }^{12}$ Mutation of Ptprq in the mouse causes deafness associated with disrupted stereociliar bundles. ${ }^{3}$ Here we report the first human mutation of PTPRQ in an extended kindred with inherited hearing loss.

\section{METHODS}

\section{Clinical evaluation}

Children with prelingual, bilateral hearing loss were ascertained through Eftah School for the Deaf in Bethlehem. Informed consent was obtained from parents and assent from older children. The project was approved by the Human Subjects Committee of Bethlehem University and by the Human Subjects Division of the University of Washington.
Audiological exams were performed on all affected family members at the Dar Al-Kalima Health and Wellness Center in Bethlehem to exclude hearing loss due to infection or trauma, to evaluate severity and laterality of the hearing loss. Vision exams were carried out in the same visits to assess the possibility of Usher syndrome. Population controls comprised 288 Palestinian adults with normal hearing and came from two sources: (1) persons attending West Bank clinics for preventive health services ( $\mathrm{n}=201)$; and (2) Palestinian individuals living in Israel who contributed DNA to the National Laboratory for the Genetics of Israeli Populations at Tel Aviv University $(n=87)$.

\section{Localisation of DFNB84}

Homozygosity mapping with Affymetrix 250K single nucleotide polymorphism (SNP) arrays was performed as previously described. ${ }^{4}$ Affected individuals in this study were children in two families, $\mathrm{CN}$ and DP. The longest deafness associated homozygous segments for these families were chr12: 74498 486-93 289627 in family CN and chr12: 65434 594-86 977739 in family DP. The SNP haplotypes in the shared region (chr12: 74498 486-86 977 739) were identical between families $\mathrm{CN}$ and DP. This locus was designated DFNB84 by the HUGO Gene Nomenclature Committee. ${ }^{4}$

\section{Mutation analysis}

The human RefSeq entry for PTPRQ (NM 001145026) was aligned to hg18 of the human genome. The genomic interval from PTPTQ intron 3 to intron 6 is inverted on hg18. This may represent an assembly error in the reference genome rather than a true structural variant. ${ }^{5}$ Primers spanning each exon and approximately $150 \mathrm{bp}$ of flanking intronic sequence were designed (additional table 1) and used to PCR amplify DNA from individuals with hearing loss and their hearing parents. PCR products were Sanger sequenced on an Applied Biosystems 3730xl as previously described. ${ }^{6}$

\section{RESULTS}

The recessive deafness locus DFNB84 was identified by SNP based homozygosity mapping in families $\mathrm{CN}$ and DP. ${ }^{5}$ Because hearing loss of affected members of families $\mathrm{CN}$ and DP mapped to the same homozygous region of chromosome 12 , family members shared historical information to determine how they might be related. They discovered that all participants from families $\mathrm{CN}$ and DP are members of the same extended kindred, henceforth referred to as family CN/DP (figure 1A). All affected individuals in family CN/DP shared 
A

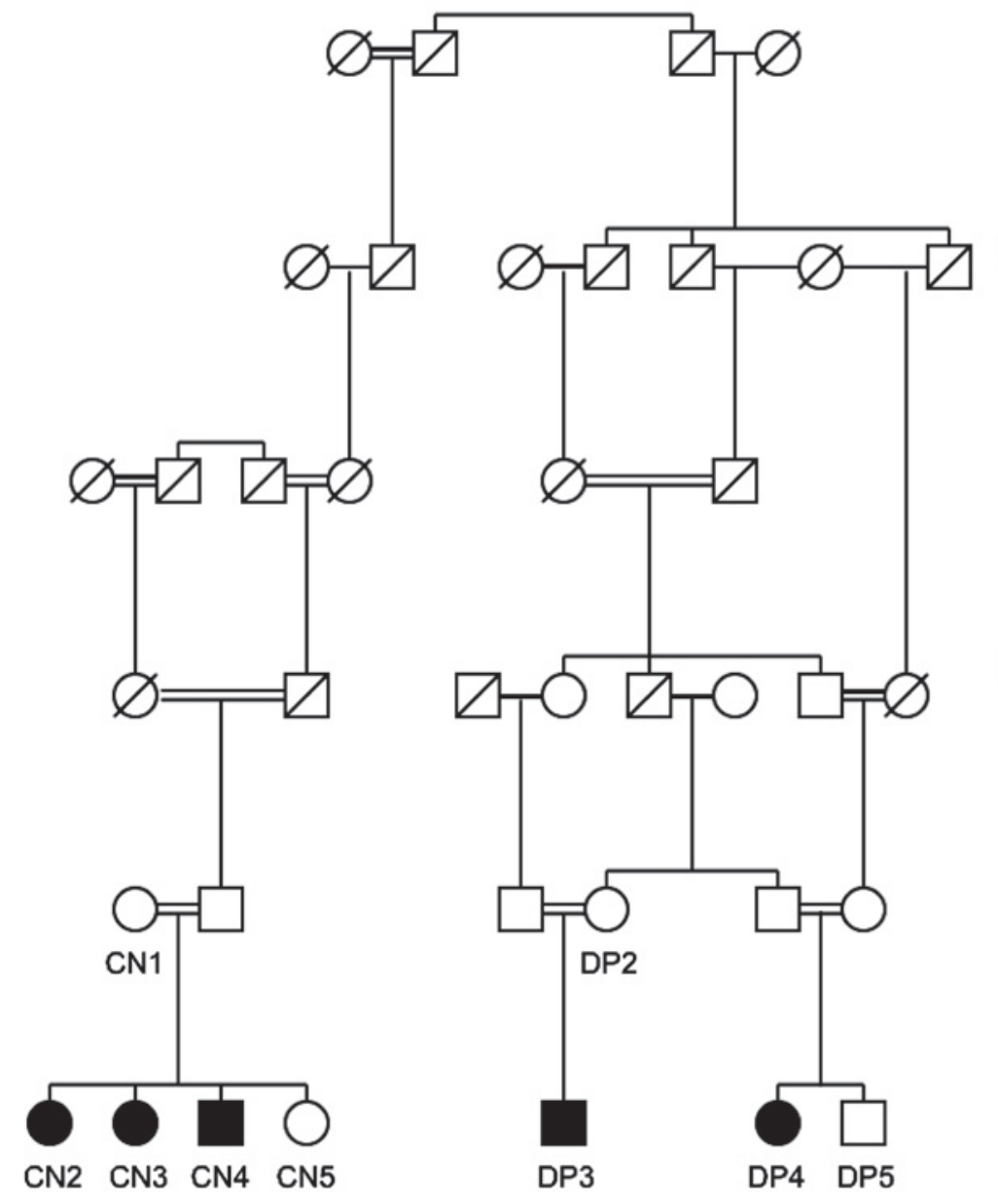

B

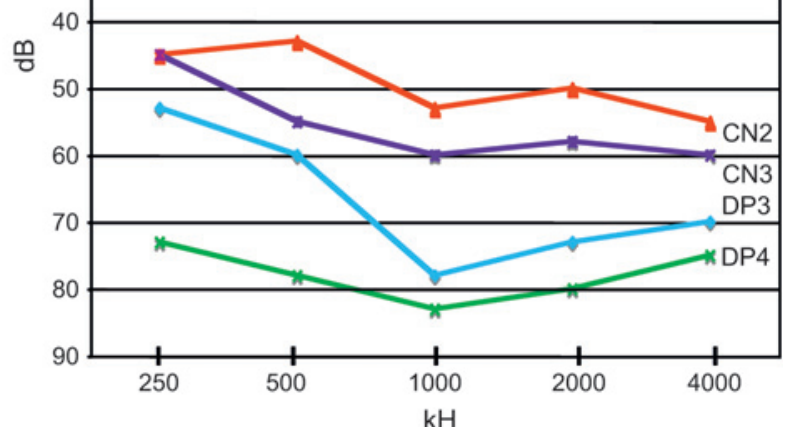

C

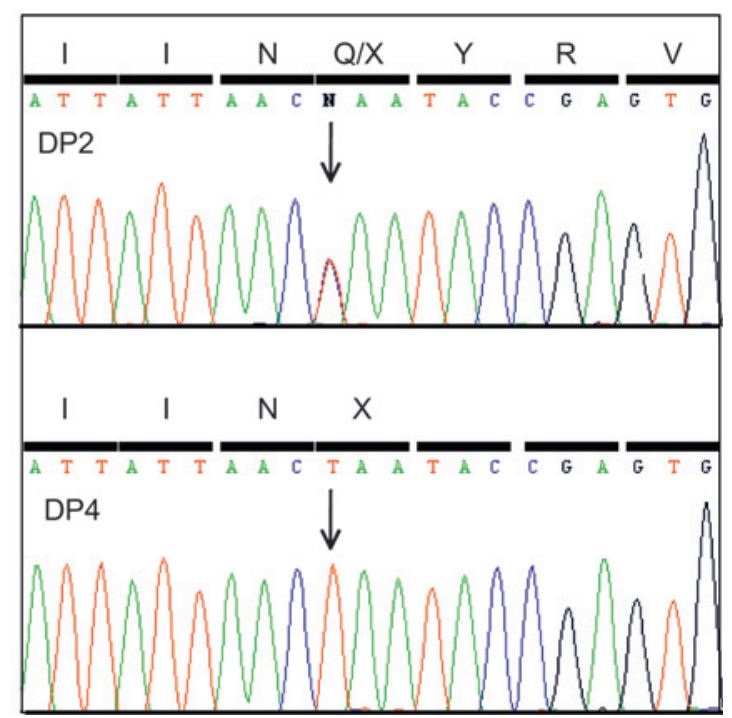

Figure 1 Inherited hearing loss in family CN/DP. (A) Pedigree of the extended kindred CN/DP, in which autosomal recessive hearing loss is linked to the DFNB84 locus. Hearing loss in affected individuals is indicated by filled symbols. Double bars between parents indicate consanguineous marriages. (B) Audiometric profiles for hearing impaired individuals from family CN/DP. Audiograms for affected individuals in family CN/DP illustrating hearing thresholds for CN2 (age 11 years), CN3 (age 15 years), DP3 (age 5 years), and DP4 (age 14 years). (C) Nonsense mutation in PTPRO. Sanger sequence trace of $P T P R Q$ exon 9. Hearing individual DP2 is heterozygous for $\mathrm{c} .1285 \mathrm{C} \rightarrow \mathrm{T}$ (chr12:79 404441 ) indicated by the arrow. This alteration is predicted to introduce stop codon TAA at codon 429, 0429X. Hearing impaired individual DP4 is homozygous for the c.1285 (p.0429X) mutation.

a homozygous haplotype at chr12: 74498 486-86 977739 (NCBI Build hg18) with lod score 4.30 under a fully penetrant recessive model. The hearing loss phenotype in all hearing impaired individuals was moderate to severe with prelingual onset, with considerable variation among family members (figure 1B). There were no signs of conductive hearing loss, as measured by air and bone conduction thresholds. None of the affected individuals had any vision problems.

A promising candidate gene in the DFNB84 linkage interval was PTPRO (protein tyrosine phosphatase receptor Q) located at bp 79362 257-79 598099 (hg18). PCR amplification and Sanger sequencing of the annotated 45 exons of PTPRO revealed c.1285C $\rightarrow \mathrm{T}$ (at chr12:79 404 441), which is predicted to introduce a premature truncation at codon 429, p.Q429X, in exon 9 (figure 1C). All hearing impaired individuals in the family were homozygous for this nonsense allele. A previously

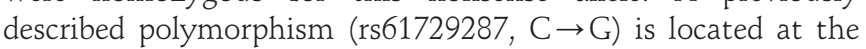
same nucleotide as the family $\mathrm{CN} / \mathrm{DP}$ nonsense mutation.
However, the $\mathrm{C} \rightarrow \mathrm{G}$ variant corresponds to a conservative p.Q429E alteration.

Screening the nonsense allele in 288 Palestinian adults with normal hearing and 218 Palestinian probands with prelingual hearing loss did not reveal any other heterozygous or homozygous individuals, suggesting that c.1285C $\rightarrow \mathrm{T}$ (p.Q429X) is a rare allele in the Palestinian West Bank population. Frequency of rs61729287 allele G was 0.03 among 218 unrelated Palestinian deaf probands and among 288 Palestinian controls, suggesting it is a benign polymorphism.

To search for additional deleterious PTPRQ alleles in the Palestinian deaf population we genotyped 218 individuals with prelingual hearing loss from consanguineous kindreds with microsatellites spanning $487 \mathrm{~kb}$ within and flanking PTPRQ. Homozygous genotypes at all four markers were observed in six probands. None of these probands shared the CN/DP haplotype. Full sequencing of $P T P R Q$ in these six individuals did not reveal any additional mutations. 
In characterising the DFNB84 genomic region, we discovered $175 \mathrm{~kb}$ upstream of PTPRQ a previously unknown gene. Upon annotation in mouse cochlea, the gene proved homologous to Otogelin, mutations in which are responsible for the mouse twister phenotype. ${ }^{7}$ We characterised this Otogelin-like gene (Otogl) and deposited it in GenBank (described in additional materials). Sequence of the human homologue OTOGL (additional figure 1) was wild type in all affected individuals of family CN/DP, excluding epistatic effects of this gene on the phenotype.

\section{DISCUSSION}

To date, 31 genes responsible for development and maintenance of hair cell bundles of the inner ear have been implicated in deafness in humans and mice. ${ }^{8}$ In mouse, homozygous loss of function of Ptprq leads to deafness associated with absence of hair cells in the basal region of the cochlea. ${ }^{3}$ Ptprq $^{-1-}$ mice age 3 months lack hair cells in the basal region of the cochlea, affecting high frequency hearing, but have no gross abnormalities in the apical end of the cochlea, affecting low frequency hearing.

The role of PTPRO in the ear has been assessed by evaluating Ptprq $^{-1-}$ mice in the context of myosin VI function. ${ }^{9}$ Myosin VI, which functions as either an actin based anchor or as a transporter, has been proposed to regulate localisation of PTPRO in stereociliar membranes. ${ }^{1}$ Myosin VI and PTPRQ co-localise in the stereocilia, suggesting that the two proteins interact. In the absence of myosin VI, PTPRO is distributed along the entire length of the stereocilia. In Ptprq-null mice, stereocilia in the apical and middle turn are fused, similar to the phenotype of Snell's waltzer myosin VI-null mice. ${ }^{10}$ Taken together, these studies suggest that PTPRO may have multiple roles: stabilising the membrane at the base of the stereocilia, regulating actin dynamics in stereocilia, and together with myosin VI, tethering the stereociliar membrane to the cytoskeleton. Given the conservation of these functions between humans and mice, it was to be expected that loss of function of PTPRQ in humans would lead to hearing loss. The present identification of mutant $P T P R Q$ for the first time in hearing impaired humans demonstrates its clinical importance.

Acknowledgements We thank the families for their participation in this study. We thank the technical staff of the Hereditary Research Laboratory of Bethlehem
University, and Carlos R Gordon of Tel Aviv University/Meir General Hospital for helpful comments and suggestions. Supported by NIH/NIDCD grant R01 DC005641.

Funding $\mathrm{NIH}$.

Competing interests None

Patient consent Obtained.

Ethics approval This study was conducted with the approval of the Human Subjects Committee of Bethlehem University and by the Human Subjects Division of the University of Washington.

Provenance and peer review Not commissioned; externally peer reviewed.

\section{REFERENCES}

1. Wright MB, Hugo C, Seifert R, Disteche CM, Bowen-Pope DF. Proliferating and migrating mesangial cells responding to injury express a novel receptor proteintyrosine phosphatase in experimental mesangial proliferative glomerulonephritis. J Biol Chem 1998;273:23929-37.

2. Oganesian A, Poot M, Daum G, Coats SA, Wright MB, Seifert RA, Bowen-Pope DF Protein tyrosine phosphatase $\mathrm{RO}$ is a phosphatidylinositol phosphatase that can regulate cell survival and proliferation. Proc Natl Acad Sci U S A 2003;100:7563-8.

3. Goodyear RJ, Legan PK, Wright MB, Marcotti W, Oganesian A, Coats SA, Booth CJ, Kros CJ, Seifert RA, Bowen-Pope DF, Richardson GP. A receptor-like inositol lipid phosphatase is required for the maturation of developing cochlear hair bundles. J Neurosci 2003:23:9208-19.

4. Shahin H, Walsh T, Abu Rayyan A, Lee MK, Higgins J, Dickel D, Lewis K, Thompson J, Carl Baker C, Nord AS, Stray S, Gurwitz D, Avraham KB, King M-C, Kanaan M. Five novel loci for inherited hearing loss mapped by SNP-based homozygosity profiles in Palestinian families. Eur J Hum Genet. Published Online First: 4 November 2009. PMID 19888295. doi:10.1038/ejhg.2009.190

5. Kidd JM, Cooper GM, Donahue WF, Hayden HS, Sampas N, Graves T, Hansen N, Teague B, Alkan C, Antonacci F, Haugen E, Zerr T, Yamada NA, Tsang P, Newman TL, Tüzün E, Cheng Z, Ebling HM, Tusneem N, David R, Gillett W, Phelps KA, Weaver M, Saranga D, Brand A, Tao W, Gustafson E, McKernan K, Chen L, Malig M, Smith JD, Korn JM, McCarroll SA, Altshuler DA, Peiffer DA, Dorschner M, Stamatoyannopoulos J Schwartz D, Nickerson DA, Mullikin JC, Wilson RK, Bruhn L, Olson MV, Kaul R, Smith DR, Eichler EE. Mapping and sequencing of structural variation from eight human genomes. Nature 2008;453:56-64.

6. Shahin H, Walsh T, Sobe T, Abu Saed J, Abu Rayan A, Lynch ED, Lee MK, Avraham KB, King MC, Kanaan M. Mutations in a novel isoform of TRIOBP that encodes a filamentous-actin binding protein are responsible for DFNB28 recessive nonsyndromic hearing loss. Am J Hum Genet 2006;78:144-52.

7. Simmler MC, Zwaenepoel I, Verpy E, Guillaud L, Elbaz C, Petit C, Panthier JJ. Twister mutant mice are defective for otogelin, a component specific to inner ear acellular membranes. Mamm Genome 2000;11:960-6.

8. Petit C, Richardson GP. Linking genes underlying deafness to hair-bundle development and function. Nat Neurosci 2009:6:703-10.

9. Sakaguchi H, Tokita J, Naoz M, Bowen-Pope D, Gov NS, Kachar B. Dynamic compartmentalization of protein tyrosine phosphatase receptor $\mathrm{Q}$ at the proximal end of stereocilia: implication of myosin VI-based transport. Cell Motil Cytoskeleton 2008;65:528-38

10. Self T, Sobe T, Copeland NG, Jenkins NA, Avraham KB, Steel KP. Role of myosin $\mathrm{VI}$ in the differentiation of cochlear hair cells. Dev Biol 1999;214:331-41. 